\title{
Magnetic Pollution of Soil Samples at Some Industrial Sites in Jos Metropolis, Plateau State, Nigeria
}

\author{
*AKANBI, ES; NASAMU, EJ \\ Department of Physics, University of Jos, Nigeria. \\ *Corresponding Author Email: akanbieti@gmail.com
}

\begin{abstract}
Magnetic susceptibility of polluted material can give a general view of the degree of heavy metal pollution, prior to a more expensive and time-consuming chemical analyses. In this study, magnetic susceptibility measurements of 40 soil samples collected from some industrial sites of Jos Metropolis, were made using MS2G Sensor connected to Bartington MS 2 susceptibility meter. Volume magnetic susceptibility values ranged from $0.00026 \times 10^{-5} \mathrm{SI}$ to $0.0650 \times 10^{-5}$ SI while low frequency mass specific susceptibility values ranged from $0.1181 \times 10^{-6} \mathrm{~m}^{3} \mathrm{~kg}^{-1}$ to $20.3 \times 10$ ${ }^{6} \mathrm{~m}^{3} \mathrm{~kg}^{-1}$. In both cases least and highest values are recorded at Zuma Steel and Dilimi respectively. Comparing low frequency mass specific susceptibility values obtained from industrial sites to that obtained from non-industrial sites, it was observed that samples 11 and 12 from JIB and all samples collected from Dilimi recorded values higher than the background soil samples thus indicating magnetic enhancement of soil at these locations by anthropogenic sources. The relationship between the volume magnetic susceptibility and mass specific susceptibility showed correlation of 0.983 implying that volume magnetic susceptibility results can be accepted in the absence of low frequency mass specific susceptibility measurement to assess magnetic pollution. The study also revealed that the magnetic behaviour of the dried soil samples collected from the industrial sites are controlled by concentration of ferrimagnetic minerals.
\end{abstract}

\section{DOI: https://dx.doi.org/10.4314/iasem.v24i2.1}

Copyright: Copyright (C) 2020 Akanbi and Nasamu. This is an open access article distributed under the Creative Commons Attribution License (CCL), which permits unrestricted use, distribution, and reproduction in any medium, provided the original work is properly cited.

Dates: Received: 16 November 2019; Revised: 11 January 2020; Accepted: 22 February 2020

Keywords: Magnetic, Pollution, Ferrimagnetic, Susceptibility, Anthropogenic, Dilimi

Soil is an important component of the environment that supports crop and plant growth and land management is the basis for having a quality soil. Soil is an important and crucial component of our environment. It is necessary for plant growth-agricultural, horticultural, forest etc. Soil studies are important in Nigeria because Nigeria which was primarily agrarian before the oil boom is seriously trying to retrace its step back to agriculture and as a result Nigerians are farming anywhere there is an available land even in industry premises. During recent years magnetic measurement (in particular magnetic susceptibility) have become a generally accepted method to map spatial distribution of pollution, identify pollution sources, provide an alternative to conventional chemical analysis because its measurements are fast, cost-effective, non-destructive, sensitive and informative (Lu et al., 2007). Therefore, the magnetic susceptibility of polluted material can give a general view of the degree of pollution, which can be mapped and studied prior to more expensive and timeconsuming chemical analyses. Many soils worldwide exhibit magnetic properties that result from the presence of iron oxides in different forms and quantities. Ferrimagnetic minerals such as magnetite and maghemite are the most magnetic of the iron oxides while paramagnetic and antiferromagnetic iron oxides such as goethite and hematite play a minor role in determining the magnetic character of a soil. Sources of magnetic minerals in soils are the parent material from which the soils are developed; in situ formation by pedogenic processes (Singer and Fine, 1989; Singer et al., 1996); Aeolian deposition of dust (Maher et al., 2003); anthropogenic processes such as industrial fly ashes (Petrovsky et al., 2001) and flood deposition. In environmental studies, magnetic susceptibility measurements have been used in determining magnetic mineral content in materials and hence monitoring environmental pollution (Petrovský et al., 2001, Blaha et al., 2008 and Chaparro et al., 2008). In addition, magnetic response of soils can serve as an effective surrogate indicator for heavy metal pollution (Ngama et al., 2011). It is highly effective to detecting industrial, traffic material and other atmospheric pollutant (Francek, 1992, Kapicka et al., 1999) and also for estimating anthropogenic pollution of soils in the urban areas (Hanesch and Scholger, 2005, Jordanova et al., 2003, Akanbi and Adoyi, 2009). Jos enjoys a temperate climate and is a hub of industrial activities in Plateau State. Notable among them are food processing companies as well as construction firms. This sector has contributed quite significantly to productive employment creation and revenue generation in Plateau state. The Dilimi 
Gangare in Jos is a hub of small-scale mechanical garages that manufacture vehicle parts and provide other mechanical services to neighbouring states and is famous for its metal works. Other industrial centres that have contributed immensely to the development of the state include the Grand cereals and oil mill limited, the Jos International Breweries (JIB) Plc, the Zuma Steel West Africa (ZSWA) the Nigerian Bottling Company, and the NASCO group. Biotite granite rocks of the Jos-Bukuru Younger Granite Complex, Basement rocks, and volcanic rocks dominate the study area. Iron-containing minerals can be found in these igneous rocks (Singer et al., 1996) and therefore the soils in this study area may contain some iron oxide. The parent material, soil age, pedogenic processes, biological activity, and soil temperature (Singer et al., 1996) affect the concentration of (magnetic) iron oxides. The aim of this study is to use magnetic susceptibility to assess soil magnetic pollution at some industrial sites in Jos Metropolis, Plateau state, North Central, Nigeria.

\section{MATERIALS AND METHOD}

Materials: Bartington MS2 meter and MS2G Sensor (Bartington Instruments Ltd., Char bury, Oxford, England), Global Positioning System (GPS), A and Gulf Electronic Weighing Balance, Notepad, markers, masking tape, sample bags shovels and a plastic spoon.

Method: Soil samples were collected from industry premises and non-industrial locations (to serve as background samples). The coordinates of each location were noted. The samples were taken to the laboratory and air-dried to remove water. $1 \mathrm{~cm}^{3}$ pots were filled for the measurement of their volume magnetic susceptibility using the Bartington MS2G sensor and volume magnetic susceptibility measurements were made using the sensor in the laboratory. MS2G sensor is for small single samples measured at low frequency only. All measurements were conducted at the most sensitive " 0.1 " setting. An air reading was performed before and after each measurement. The values for volume magnetic susceptibility for five samples from each location were measured and the average volume magnetic susceptibility ( $\kappa)$ calculated. Masses for these samples for each location were measured and the average mass calculated. The bulk density of a sample was calculated by dividing mass of sample by volume of sample. This was easy to calculate because all the MS2G samples are usually measured in pots of $1 \mathrm{~cm}^{3}$. Therefore, provided the pots are full, only the mass values vary. Low frequency mass specific susceptibility was then calculated using $\chi_{\text {lf }}=\kappa / \rho$

Where $\kappa$ is the volume magnetic susceptibility at low frequency and $\rho$ is the bulk density of the sample. The dimension of mass susceptibility is therefore $\mathrm{m}^{3} / \mathrm{kg}$.

\section{RESULT AND DISCUSSION}

The results for volume magnetic susceptibility and low frequency mass specific susceptibility measurements is presented in Table 1. Volume magnetic susceptibility values range from $0.00026 \times 10^{-5} \mathrm{SI}$ to $0.0650 \times 10^{-5}$ SI while low frequency mass specific susceptibility values range from $0.1181 \times 10^{-6} \mathrm{~m}^{3} \mathrm{~kg}^{-1}$ to $20.3 \times 10^{-6} \mathrm{~m}^{3} \mathrm{~kg}^{-1}$. In both cases least and highest values are recorded at Zuma Steel and Dilimi respectively. The mean low frequency mass specific susceptibility of the different industrial sites decreases in the following order: Dilimi $>$ JIB $>$ Nasco $>$ Cocacola $>$ Zuma Steel $>$ Grand Cereal. There is significant difference in volume magnetic susceptibility and low frequency mass specific susceptibility values as seen in Table 1. The difference is because volume magnetic susceptibility is magnetization per unit volume while for mass specific susceptibility the bulk density of each sample is considered (Equation 1) as these samples are made of different particles with different masses depending on the makeup of the sample. These samples will therefore have different masses and hence different bulk densities. According to Dearing (1999), single sample susceptibility is not normally expressed on a volumetric basis, but on a basis of dry mass and some studies have used single homogeneous sample volume susceptibility values, notably studies of deepsea sediments, but only where density is constant or where data are used to form ratios, which are independent of density. The relationship between the volume magnetic susceptibility and mass specific susceptibility (Fig 1) for this study show a high positive correlation with correlation coefficient of 0.983 . The higher the absolute value of the correlation coefficient, the stronger the relationship and the sign of the correlation coefficient represents the direction of the relationship. This implies that in this study area that the volume magnetic susceptibility results can be accepted in the absence of low frequency mass specific susceptibility measurement to assess magnetic pollution. An infinite number of environmental conditions give rise to a very wide range of mineralogies and magnetic susceptibility values. According to Dearing (1999), as a rule-of-thumb, mass specific susceptibility values taken at low frequency, $\chi_{\mathrm{lf}}$, of any sample with a value less than $0.1 \times 10^{-}$ ${ }^{6} \mathrm{~m}^{3} \mathrm{~kg}^{-1}$ is controlled by the concentration of paramagnetic minerals and for values greater than this by ferrimagnetic minerals. 
Table 1: Magnetic Susceptibility Result

\begin{tabular}{|c|c|c|c|c|c|}
\hline S/No. Location & $\begin{array}{l}\text { Longitude } \\
\left({ }^{\circ} \mathrm{E}\right)\end{array}$ & $\begin{array}{l}\text { Latitude } \\
\left({ }^{\circ} \mathrm{N}\right)\end{array}$ & $\begin{array}{l}\text { Volume mag. } \\
\text { Susceptibility, } \kappa \\
\left(\times 10^{-5} \mathrm{SI}\right)\end{array}$ & $\begin{array}{l}\text { Mass specific } \\
\text { Magnetic Susc, } \\
\chi_{1 \mathrm{lf}}\left(\mathrm{x} 10^{-6} \mathrm{~m}^{3} \mathrm{~kg}^{1}\right)\end{array}$ & $\begin{array}{l}\text { Magnetic } \\
\text { Behaviour of } \\
\text { samples }\end{array}$ \\
\hline 1. Grand cereal 1 & 8.8556 & 9.7600 & 0.00172 & 0.7166 & Ferrimagnetic \\
\hline 2. Grand cereal 2 & 8.8854 & 9.7594 & 0.00147 & 0.6125 & Ferrimagnetic \\
\hline 3. Grand cereal 3 & 8.8516 & 9.7572 & 0.00147 & 0.6129 & Ferrimagnetic \\
\hline 4. Grand cereal 4 & 8.8544 & 9.7591 & 0.00787 & 2.8107 & Ferrimagnetic \\
\hline 5. Grand cereal 5 & 8.8527 & 9.7577 & 0.00147 & 0.6125 & Ferrimagnetic \\
\hline 6. Grand cereal 6 & 8.8550 & 9.7594 & 0.00580 & 2.9000 & Ferrimagnetic \\
\hline 7. Grand cereal 7 & 8.8553 & 9.7594 & 0.00203 & 0.7807 & Ferrimagnetic \\
\hline 8. JIB & 8.8769 & 9.8691 & 0.00564 & 1.9380 & Ferrimagnetic \\
\hline 9. JIB & 8.8767 & 9.8694 & 0.01100 & 4.5833 & Ferrimagnetic \\
\hline 10. JIB & 8.8763 & 9.8686 & 0.00241 & 0.8607 & Ferrimagnetic \\
\hline 11. JIB & 8.8738 & 986583 & 0.01665 & 6.9375 & Ferrimagnetic \\
\hline 12. JIB & 8.8738 & 9.8655 & 0.01530 & 7.2857 & Ferrimagnetic \\
\hline 13. JIB & 8.8730 & 9.8655 & 0.00297 & 2.5826 & Ferrimagnetic \\
\hline 14. Zuma Steel & 8.8802 & 9.8616 & 0.01130 & 4.1851 & Ferrimagnetic \\
\hline 15. Zuma Steel & 8.8738 & 9.8652 & 0.00202 & 0.8782 & Ferrimagnetic \\
\hline 16. Zuma Steel & 8.8827 & 9.8619 & 0.00138 & 0.5520 & Ferrimagnetic \\
\hline 17. Zuma Steel & 8.8819 & 9.8619 & 0.00096 & 0.3840 & Ferrimagnetic \\
\hline 18. Zuma Steel & 8.8727 & 9.8694 & 0.00026 & 0.1181 & Ferrimagnetic \\
\hline 19. Zuma Steel & 8.8736 & 9.8655 & 0.00436 & 2.8100 & Ferrimagnetic \\
\hline 20. Nasco/ Old airport & 8.8730 & 9.8694 & 0.00346 & 1.6476 & Ferrimagnetic \\
\hline 21. Nasco/ Old airport & 8.8730 & 9.9055 & 0.00335 & 1.4565 & Ferrimagnetic \\
\hline 22. Nasco/ Old airport & 8.8733 & 9.9083 & 0.00394 & 1.9700 & Ferrimagnetic \\
\hline 23. Nasco/ Old airport & 8.8733 & 9.8730 & 0.00570 & 2.5909 & Ferrimagnetic \\
\hline 24. Nasco/ Old airport & 8.8708 & 9.8897 & 0.00504 & 2.5400 & Ferrimagnetic \\
\hline 25. Nasco/ Old airport & 8.8702 & 9.8722 & 0.00510 & 2.2113 & Ferrimagnetic \\
\hline 26. Nasco/ Old airport & 8.8727 & 9.8725 & 0.00689 & 2.9956 & Ferrimagnetic \\
\hline 27. Coca-cola & 8.8741 & 9.8733 & 0.00631 & 2.5240 & Ferrimagnetic \\
\hline 28. Coca-cola & 8.8716 & 9.8730 & 0.00591 & 2.3791 & Ferrimagnetic \\
\hline 29. Coca-cola & 8.8716 & 9.8706 & 0.00557 & 2.4652 & Ferrimagnetic \\
\hline 30. Coca-cola & 8.8700 & 9.8725 & 0.00682 & 3.4100 & Ferrimagnetic \\
\hline 31. Coca-cola & 8.9194 & 9.8363 & 0.00107 & 0.3566 & Ferrimagnetic \\
\hline 32. Coca-cola & 8.9197 & 9.8369 & 0.00185 & 0.8043 & Ferrimagnetic \\
\hline 33. Dilimi & 8.8950 & 9.9200 & 0.05474 & 18.8756 & Ferrimagnetic \\
\hline 34. Dilimi & 8.8952 & 9.9211 & 0.03059 & 10.9250 & Ferrimagnetic \\
\hline 35. Dilimi & 8.8961 & 9.9225 & 0.06500 & 20.3125 & Ferrimagnetic \\
\hline 36. Dilimi & 8.8963 & 9.9227 & 0.04154 & 14.8357 & Ferrimagnetic \\
\hline 37. Dilimi & 8.8961 & 9.9244 & 0.04871 & 13.1648 & Ferrimagnetic \\
\hline 38. Dilimi & 8.8950 & 9.9225 & 0.03177 & 10.5900 & Ferrimagnetic \\
\hline 39. Dilimi & 8.8966 & 9.9236 & 0.05396 & 16.8625 & Ferrimagnetic \\
\hline 40. Dilimi & 8.8941 & 9.9238 & 0.06318 & 19.1454 & Ferrimagnetic \\
\hline
\end{tabular}

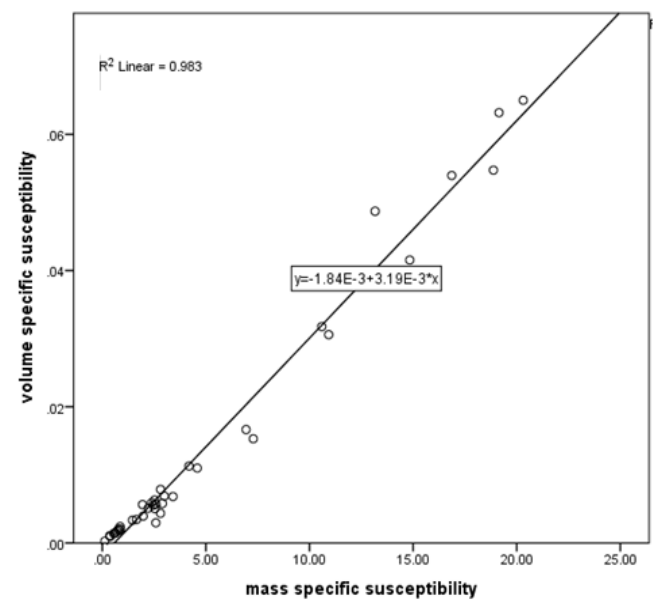

Fig 1: Relationship between Volume Magnetic Susceptibility and Mass Specific Susceptibility
In addition, negative values are controlled by the dominance of diamagnetic There are exceptions though to this rule, especially in some weak samples where the susceptibility may be controlled by minute concentrations of ferrimagnetic minerals (Dearing, 1999). Table 1 also shows the magnetic behaviour of the dried soil samples and it was observed that each sample collected from the industrial sites are controlled by concentration of ferrimagnetic minerals. Soil samples collected from non-industrial sites were measured for background mass specific susceptibility as background susceptibility value should always be determined in an unimpacted soil in order to evaluate the relative enhancement due to anthropogenic influence (Lu et al., 2007). These values are shown in Table 2. 


\begin{tabular}{|c|c|c|c|c|}
\hline $\begin{array}{l}\text { Sample } \\
\text { Id }\end{array}$ & $\begin{array}{l}\text { Longitude } \\
\left({ }^{\circ} \mathrm{E}\right)\end{array}$ & $\begin{array}{l}\text { Latitude } \\
\left({ }^{\circ} \mathrm{N}\right)\end{array}$ & $\begin{array}{l}\text { Volume susceptibility } \\
\mathrm{\kappa}\left(\mathrm{x} 10^{-5}\right) \mathrm{SI}\end{array}$ & $\begin{array}{l}\text { Mass Specific Susceptibility, } \\
\chi_{\mathrm{lf}}\left(\times 10^{-6} \mathrm{~m}^{3} \mathrm{~kg}^{-1}\right)\end{array}$ \\
\hline A & 8.965 & 10.044 & 0.00585 & 5.318 \\
\hline B & 9.008 & 9.813 & 0.006926 & 6.296 \\
\hline
\end{tabular}

The low frequency mass specific susceptibility values of background soil samples A and B are 5.381 x 10${ }^{6} \mathrm{~m}^{3} \mathrm{~kg}^{-1}$ and $6.926 \times 10^{-6} \mathrm{~m}^{3} \mathrm{~kg}^{-1}$ respectively. These values were compared with the low frequency mass specific susceptibility values of the soil samples from the various industrial sites and it was observed that samples 11 and 12 from JIB and all samples collected from Dilimi recorded values higher than the background soil samples thus indicating magnetic enhancement of soil at these locations by anthropogenic sources.

Conclusion: In this study to assess magnetic pollution at industrial sites in Jos Metropolis North Central Nigeria, the result of the volume magnetic susceptibility and low frequency mass specific susceptibility data reveal magnetic pollution at some locations at JIB and all locations at Dilimi. This study also reveals that the volume magnetic susceptibility results can be accepted in the absence of low frequency mass specific susceptibility measurement to assess magnetic pollution.

\section{REFERENCES}

Akanbi, ES; Adoyi, IM (2009). Determination of Magnetic Susceptibility of Soil Samples around Jos Area, Nigeria. Nigerian Journal of Technological Research (NJTR), 4 (2): 222-232.

Blaha, U; Appel, E; Stanjek, H (2008). Determination of anthropogenic boundary depth in industrially polluted soil and semi-quantification of heavy metal loads using magnetic susceptibility. Environ. Pollut., 156: 278-289.

Chaparro, MAE; Marinelli, C; Sinito, AM (2008). Multivariate techniques as alternative statistical tools applied to magnetic proxies for pollution: a case study from Argentina and Antarctica. Environ. Geol., 54: 365-371.

Dearing, JA (1999). Environmental magnetic susceptibility using the Bartington MS2 system. $2^{\text {nd }}$ edn, chi Publishing, England.

Francek, MA (1992). Soil Lead levels in a Small town environment: a case study from Mt. Pleasant Michiga. Environ. Pollut. 76: 251-257.

Hanesch, M; Scholger, R (2005). The influence of Soil type on the Magnetic Susceptibility measured throughout Soil profiles. Geophys. J. Int., 16: 5056.

Jordanova, NV; Jordanova, DV; Veneva, L; Yorova, K; Petrovsky, E (2003). Magnetic response of soils and vegetation to heavy metal pollution; a case study. Environ. Sci. Technol., 37:441744234.

Kapicka, A; Petrovsky, E; Ustjak, S; Machakova, K (1999). Proxy mapping of fly-ash Pollution of soils around a burning power plant: a case study in the Czech republic. J. Geochem. Explor. 66: 291-297.

Lu, SG; Bai, SQ; Xue, QF (2007). Magnetic properties as indicators of heavy metals Pollution in urban topsoil: a case study from the city of Luoyang, China. Geophys. J. Int., 171: 603-612.

Maher, BA; Hu, M; Roberts, HM; Wintle, AG (2003). Holocene loess accumulation and soil development at the western edge of the Chinese Loess Plateau: Implications for magnetic Proxies of paleo rainfall. Quat. Sci. Rev, 22: 445-451.

Ngama, JE; Lasur, MK; Akanbi, ES (2011). Magnetic Susceptibility Levels of Cassiterite Tailings in Jos, Plateau state, North-Central Nigeria. African Journal of Natural Sciences (AJNS), 14: 33-37.

Petrovsky, E; Kapicka, A; Jordanova, N; Knab, M; Hoffmann, V (2001). Low-field Magnetic susceptibility: A proxy method of estimating increased Population of different environmental systems. Environ. Geol, 39: 312-318.

Singer, MJ; Fine, P (1989). Pedogenic factors affecting magnetic susceptibility of Northern California soils. Soil Sci. Soc. Am. J., 53:11191127.

Singer, MJ; Verosub, KL; Fine, P; TenPas, J (1996). A conceptual model for the enhancement of magnetic susceptibility in soils. Quat. Int., 34-36: 243-248. 